\title{
¿El virus afecta "a todos (y a todas) por igual”? Una mirada crítica acerca del trabajo doméstico remunerado en Argentina en tiempos de pandemia por COVID-19
}

\section{Does the Virus Affect “Everyone Equally”? A Critical Look at Paid Domestic Work in Argentina in Times of the GOvID-19 Pandemic}

\author{
Verónica L. Casas ${ }^{1^{*}}$ \\ Hernán M. Palermo ${ }^{2}$ \\ 1* Centro de Estudios e Investigaciones Laborales, CEIL-CONICET, Buenos Aires, Argentina. \\ email: veronika.casas@gmail.com https://orcid.org/oooo-0003-3744-2235 \\ ${ }^{2}$ Centro de Estudios e Investigaciones Laborales, CEIL-CONICET/UBA, Buenos Aires, \\ Argentina. email: hernanpalermo@gmail.com (10 https://orcid.org/oooo-0003-0414-7352. \\ *Autora para correspondencia
}

Recibido: 28 de agosto de 2020

Aceptado: 26 de abril de 2021

Publicado: 31 de mayo de 2021

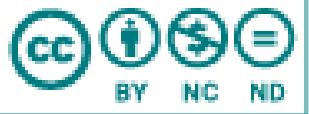

Esta obra está protegida bajo una Licencia Creative Commons Atribución-NoComercialSinDerivadas 4.0 Internacional (CC BY-NC-ND 4.0)

\section{Resumen}

El propósito del presente trabajo es analizar el impacto de la pandemia del COVID-19 en el sector del empleo doméstico remunerado en Argentina. En términos metodológicos recurrimos a la triangulación de datos de carácter cuantitativo y cualitativo: por un lado, desarrollamos una encuesta virtual, y por otro, realizamos entrevistas en línea a mujeres que trabajan en casas particulares. Podemos afirmar que el contexto de pandemia empeoró los procesos de precarización estructural propios de este sector. Asimismo, el discurso de la

CÓMO CITAR: Casas, Verónica y Palermo, Hernán M. (2021). ¿El virus afecta “a todos (y a todas) por igual"? Una mirada crítica acerca del trabajo doméstico remunerado en Argentina en tiempos de pandemia por COVID-19. Revista Interdisciplinaria de Estudios de Género de El Colegio de México, 7, e699. doi: http://dx.doi.org/10.24201/reg.v711.699

http://estudiosdegenero.colmex.mx 
pandemia constituido a partir de los significantes de la masculinidad profundizó los procesos de desvalorización social de la actividad, al contrastar con los significantes "naturalmente" femeninos asociados al trabajo doméstico.

Palabras clave: género y trabajo; trabajo doméstico; trabajadoras domésticas; desigualdad.

\begin{abstract}
This paper analyzes the impact of the COVID-19 pandemic on the paid domestic employment sector in Argentina. Our methodological approach triangulates quantitative and qualitative data through an online survey and by conducting online interviews with women employed in private homes. Our finding was that the pandemic situation exacerbated this sector's characteristic structural precariousness. Furthermore, pandemic discourses structured around the production of the signifiers of masculinity further devalued this work from a social perspective, in contrast to the "naturally" feminine signifiers associated with domestic work.
\end{abstract}

Key words: gender and work; domestic work; domestic workers; inequality.

\title{
Introducción
}

Primero en China, luego en Europa y por último en América Latina, la pandemia ${ }^{1}$ del COVID19 puso en jaque al mundo entero. La irrupción del virus obligó a los diferentes gobiernos a establecer modalidades de aislamiento o distanciamiento social, que al momento de escribir este artículo se revela como el modo más efectivo para enfrentar la transmisión, al menos hasta la vacunación de una gran parte de la población. Además de la cantidad acelerada de contagios y fallecimientos causados por la pandemia, se han puesto en evidencia procesos de desigualdad, pobreza estructural, falta de acceso a servicios de salud y desempleo — entre otros problemasen diversas partes del globo, pero especialmente en regiones como la de América Latina.

${ }^{1}$ El 11 de marzo de 2020 la Organización Mundial de la Salud (OMS) declaró el estado de pandemia causada por el coronavirus (COVID-19). 
En Argentina, el ingreso del virus estuvo ligado con el retorno al país de sectores de las clases media y alta que habían viajado al exterior durante los meses de verano. El primer contagio se registró oficialmente el 3 de marzo ${ }^{2}$. El desarrollo de la primera etapa de transmisión tuvo su origen mayoritariamente en casos importados — ciudadanos que viajaron al exterior-o en personas que tuvieron contacto directo con aquellos que viajaron. El 20 de marzo, con menos de 200 casos detectados, el gobierno nacional, a través del Decreto núm. 297/2020, estableció el Aislamiento Social Preventivo y Obligatorio (ASPO) en todo el territorio nacional, que determinó que las personas debían permanecer en sus residencias, se prohibió la circulación, y se suspendieron eventos culturales, recreativos, deportivos, religiosos y de cualquier otra índole que implicaran la concurrencia de personas. Sólo quedaron exceptuados de la prohibición de circulación quienes prestaran actividades esenciales en la emergencia. El 23 de marzo se detectó oficialmente el primer caso de transmisión comunitaria del virus. Cuatro meses después, ésta comenzó a ser la principal forma de contagio en el país, especialmente en grandes conglomerados urbanos. La nueva fase empezó a afectar de forma multidimensional y en mayor profundidad a los sectores más vulnerables y precarizados de la sociedad causando, particularmente, diversos desajustes en las lógicas cotidianas de trabajo en un mundo que avizoraba una de las peores crisis desde mediados de los años 70 . Cabe destacar, sobre este aspecto, que el gobierno nacional implementó una batería de políticas de intervención orientadas a mitigar la crisis, sobre todo en los sectores más expuestos a sus efectos ${ }^{3}$.

Uno de los grupos más vulnerables, que ha sufrido de manera directa el impacto de la pandemia, es el de las trabajadoras ${ }^{4}$ domésticas remuneradas. Se trata de un sector estructuralmente

\footnotetext{
${ }^{2}$ Ministerio de Salud de la Nación (2020).

${ }^{3}$ Entre las principales medidas se pueden mencionar: la doble indemnización por despidos (establecida previamente a través del Decreto núm. 34/19 y prorrogada durante el contexto de pandemia), el congelamiento de tarifas y la prohibición de cortes de servicios públicos (Decreto núm. 311/20). El programa de Asistencia de Emergencia al Trabajo y la Producción, ATP (Decreto núm. 332/20) — que consistió en dar facilidades a empresas para las contribuciones patronales e incluso el pago por parte del Estado del $50 \%$ de los salarios de los trabajadores y prestaciones por desempleo. El Ingreso Familiar de Emergencia, IFE (Decreto núm. 310/20) o prestación de emergencia destinada a personas que se encuentren desocupadas, que trabajen en la informalidad, sean monotributistas o trabajadoras de casas particulares.

${ }^{4}$ Dado que el sector de trabajo doméstico remunerado está compuesto mayoritariamente por mujeres, en este artículo nos referiremos a trabajadoras — en femenino - como denominación universal, incluyendo a trabajadores varones y de otras identidades. De la misma manera, para evitar la duplicidad se utilizará el término empleadores de manera general.
} 
desigual en términos comparativos en el mundo del trabajo ${ }^{5}$, donde la violencia de la desocupación, la incertidumbre laboral y la precarización adquieren especificidades. Esta desigualdad es producto de la intersección de dimensiones de género, clase y étnico-raciales entre otras - que definen a este sector laboral tan particular (Magliano, 2015, 2017).

Una vez establecido el ASPO en todo el territorio nacional, dentro del trabajo doméstico remunerado se pueden identificar dos situaciones. Por un lado, la atención y cuidado de personas con discapacidad, personas mayores, niños, niñas y adolescentes fue declarada actividad esencial —Decreto núm. 297/2020 art. 6, inc.5-, por ende, las trabajadoras que desempeñaran esas tareas estaban habilitadas para hacerlo, a menos que pertenecieran a grupos considerados de riesgo o tuvieran infantes en edad escolar. Y, por otro lado, a quienes llevaban adelante el resto de las actividades —es decir, tareas de limpieza, mantenimiento u otras que son típicas del hogar-, se les prohibió concurrir a su lugar o lugares de trabajo manteniendo la obligación de sus empleadores de abonar su remuneración completa.

El propósito del presente trabajo es abordar el impacto de la crisis del COVID-19 en el sector de empleo doméstico remunerado en Argentina, con énfasis en el Área Metropolitana de Buenos Aires (AMBA), a partir del análisis de datos que arrojó una encuesta realizada durante los primeros meses del ASPO y de entrevistas con trabajadoras. En particular, en este artículo analizaremos las consecuencias objetivas en materia laboral y subjetivas en relación con el discurso pandémico. En primer lugar, en lo que respecta a las consecuencias objetivas, plantearemos que las desigualdades constitutivas del sector se hicieron evidentes ante la crisis desatada por la pandemia. En segundo lugar, respecto de las consecuencias subjetivas, observaremos cómo la crisis ha reforzado dos construcciones de sentido recurrentes en torno a

\footnotetext{
${ }^{5}$ Acerca del mundo del trabajo en Argentina, creemos conveniente caracterizar brevemente los últimos años. El período de gobiernos kirchneristas (2003-2015) estuvo marcado por el objetivo de diseñar un esquema de políticas laborales tendientes a que el empleo volviera a ocupar un rol central en los procesos de inclusión social. Sin embargo, las deudas pendientes que no alcanzaron a atenderse en materia laboral (Trajtemberg, 2016) fueron la condición de posibilidad para que la gestión siguiente especulara con una reforma laboral y previsional de corte neoliberal. El recambio de gobierno en 2015 con la Presidencia de Mauricio Macri implicó el retorno al predominio de los rasgos de política económica neoliberales en el esquema macroeconómico, lo que generó una crisis de la estructura productiva, el aumento de la desocupación, una significativa pérdida del poder adquisitivo de los salarios, aumento de la pobreza y la indigencia y un fuerte proceso de persecución de trabajadores estigmatizados por un fuerte discurso antitrabajador.
} 
la pandemia ${ }^{6}$. Por un lado, aquella que relativiza las desigualdades estructurales con la idea de que "el virus nos afecta a todos (y todas) por igual", albergando una mirada biologicista característica del modelo médico hegemónico (Menéndez, 1988), cuya premisa consiste en que somos cuerpos vivientes agredidos por un agente biológico externo. Y por el otro, el relato masculinizado que reproduce la noción de "guerra", ponderando la virilización de las prácticas llevadas adelante para "combatir" la pandemia, al tiempo que profundiza la desvalorización de los trabajos feminizados. En definitiva, ambas construcciones de sentido refuerzan la invisibilización estructural del sector y el impacto sobre las mismas a partir de la pandemia del COVID-19.

Para efectuar la indagación que presentamos, recurrimos a la triangulación de datos cuantitativos y cualitativos obtenidos a partir de un proceso de trabajo de campo mediado por las tecnologías digitales (Ardèvol, Estalella y Domínguez, 2008). Para el trabajo cuantitativo aplicamos una encuesta virtual ${ }^{7}$ cuya metodología fue un cuestionario autoadministrado anónimo a través de una plataforma online, con preguntas cerradas y abiertas y distribuido a través de las redes sociales. En una segunda etapa, profundizamos con entrevistas a trabajadoras domésticas remuneradas. Las entrevistas semiestructuradas fueron realizadas de manera virtual mediante el uso de la plataforma Zoom o a través de videollamadas de WhatsApp. Asimismo, hemos registrado y analizado diversas interacciones públicas en grupos de Facebook específicos para trabajadoras ${ }^{8}$.

Este artículo contiene cuatro secciones. En la primera, exponemos las características del sector de trabajo doméstico remunerado en Argentina, dando cuenta de las condiciones precarias, desiguales y de bajos salarios. En la segunda, reunimos los principales resultados de la encuesta realizada y observamos cómo la pandemia impactó en la vida laboral de las trabajadoras. En la

\footnotetext{
${ }^{6}$ Estas nociones se replican en los medios de comunicación y en gran parte de la dirigencia política a cargo del manejo de la emergencia desatada por la pandemia del COVID-19.

${ }^{7}$ Los principales resultados se pueden encontrar en: (2020). "Informe preliminar de la encuesta a trabajadoras de casas particulares y su situación laboral en el contexto de aislamiento por la pandemia de COVID-19 en Argentina". CEIL-CONICET y el Programa Salud, Subjetividad y Trabajo de la UNLa.

${ }^{8}$ Los grupos de Facebook son espacios dentro de esta red social donde personas con determinados intereses en común interactúan y comparten contenido e información (entre otras posibilidades). Para el presente trabajo, previa presentación con quienes administraban dos de los grupos elegidos de trabajadoras domésticas remuneradas, realizamos un trabajo sistemático de registro.
} 
tercera, analizamos la manera en que los discursos construidos en torno a la pandemia refuerzan las condiciones de invisibilización y desvalorización de este trabajo. Y, por último, en la cuarta parte esbozamos nuestras reflexiones a partir de las líneas indagadas acerca de esta labor, que paradójicamente es esencial, pero a su vez profundamente desigual.

\section{El trabajo doméstico remunerado en Argentina: Condiciones estructurales de precariedad e informalidad}

El trabajo doméstico remunerado comprende tareas como las de limpieza, lavado y planchado, cocción de alimentos, cuidado de infantes, personas de la tercera edad o el cuidado no terapéutico de personas enfermas, entre otras; se realiza en los hogares y a cambio quien lo desempeña percibe una retribución monetaria. Nos referimos a actividades que históricamente - a partir del proceso de industrialización y con el advenimiento del capitalismo- se han adjudicado al ámbito privado de la familia y a las mujeres. Es decir, un proceso que inauguró una nueva división sexual del trabajo que confinó a las mujeres al trabajo reproductivo, negándoles el salario como una expresión de éste al colocarlo en una esfera de no-trabajo (Federici, 2010,2018). Y tal como señalan Borderías, Carrasco y Torns (2011), se instauró una ideología de la domesticidad que otorgó la responsabilidad "natural" de los cuidados a las mujeres. Este rol no sólo se limita a quien debe ejecutar las tareas, sino que las mujeres se convirtieron en el sujeto encargado de su organización, a quien le está "vedado retirarse, y menos aún pensar en sí y para sí” (Murillo, 1996, p. 2). En ese sentido, la domesticidad debe ser pensada, siguiendo a Murillo, como una actitud que expresa una manera de vinculación específica y que es sustentada por un aprendizaje de género. Por lo expuesto, el ámbito doméstico y las tareas que implica sea realizado con o sin remuneración, "es un trabajo devaluado, en el sentido de que no tiene reconocimiento social y si se remunera los salarios son de los más bajos del mercado" (Borderías, Carrasco y Torns, 2011, p. 72). El sector del trabajo doméstico remunerado se estructura sobre la base de cómo es significado y valorado. Efectivamente el trabajo doméstico remunerado es uno de los empleos más precarios, con peores salarios y más carentes de regulación y acceso a la seguridad social (Lexartza, Chaves, Carcedo, 2016). A las conocidas brechas salariales entre hombres y mujeres, se le suma la propia de esta actividad, considerada un trabajo "no calificado". 
En Argentina lo realizan 1.4 millones de trabajadoras (López Mourelo, 2020). Agrupa a un 17\% de mujeres ocupadas y $23 \%$ de asalariadas (MTEYSS, 2005; Poblete, 2014) y es una de las principales actividades de las mujeres asalariadas en nuestro país y un sector feminizado casi en su totalidad. En promedio, las trabajadoras que se desempeñan en el servicio doméstico son mujeres adultas, con secundaria incompleta y en su mayoría "jefas de hogar" (MTEYSS, 2005).

En el marco de políticas de Estado que tenían como objetivo la "extensión del empleo registrado y la ampliación de derechos a colectivos vulnerables" (MTEySS, 2014b), en marzo del 2013 se sancionó la Ley núm. 26.844 "Régimen Especial de Contrato de Trabajo para el Personal de Casas Particulares", que significó la extensión de derechos laborales y sociales a todas las trabajadoras domésticas, sin importar el número de horas trabajadas. La reglamentación que regulaba a este sector, hasta ese año, era el Decreto-Ley 326 de 1956 - promulgado durante la dictadura de Aramburu - que sólo incluía a aquellas personas que trabajaran como mínimo cuatro horas diarias cuatro veces a la semana. Es decir, que muchas trabajadoras quedaban por fuera de la legislación ya que no cumplían con los requisitos. Asimismo, el 24 de marzo de 2014 nuestro país ratificó el Convenio núm. 189 sobre "las trabajadoras y los trabajadores domésticos", redactado en la centésima Conferencia Internacional de Trabajo. Este marco de derechos constituyó un avance significativo para las trabajadoras de casas particulares.

De la ley vigente podemos destacar la creación de la Comisión Nacional de Trabajo en Casas Particulares (CNTCP), un órgano tripartito - con representantes del Estado, sindicatos y empleadores - que fija la escala de salarios mínimos y la ampliación de derechos: regulación de la jornada laboral, vacaciones pagadas, salario anual complementario, licencias - entre ellas por maternidad-, indemnización por despido sin causa, pago de horas extras, entre otros. También para las empleadas que están registradas establece la posibilidad de acceder a una Obra Social ${ }^{9}$, aportes jubilatorios y contar con Aseguradora de Riesgos de Trabajo (ART).

\footnotetext{
${ }^{9}$ En Argentina, el sistema de salud existe en dos formatos: uno universal — salud pública-y otro contributivo. El contributivo a su vez se divide en: 1) sistema obligatorio - obras sociales-, asociado a los sindicatos o a colegios profesionales; 2) sistema de seguros privados voluntario, es decir la medicina de prepaga. Las obras sociales funcionan a través de dos mecanismos: los aportes de los empleadores a partir de una relación de dependencia, y los de las trabajadoras a través de regímenes especiales, como los monotributistas. Es preciso señalar que solamente para las trabajadoras que laboran más de 16 horas semanales, el aporte obligatorio del empleador cubre el total de los pagos mínimos mensuales requeridos para acceder a una obra social. En caso de estar registrada en varios hogares, se pueden sumar esos aportes. Si la trabajadora no completa esas 16 horas
} 
En cuanto al acceso a la seguridad social, es necesario destacar también que el hecho de estar registrada no es incompatible con el cobro de asignaciones familiares otorgadas por la Administración Nacional de la Seguridad Social (ANSES) tales como: Asignación por Embarazo para Protección Social ${ }^{10}$, Asignación Familiar por Maternidad ${ }^{11}$, Asignación Universal por Hijo para Protección Social ${ }^{12}$, en todos los casos, para el personal doméstico no se aplica el techo del salario mínimo vital y móvil que sí se aplica a trabajadores no registrados.

No obstante, pese al gran avance de derechos en la última década, el sector sigue padeciendo una gran informalidad. En la actualidad, el 76.8\% de las trabajadoras no está registrada (ECETSS, 2018). Hay que tener en cuenta que, además de la falta de derechos laborales básicos, quienes no están registradas tienen un salario mensual 48\% menor que las que sí lo están (Pereyra, 2012). A la alta informalidad y bajos salarios, quisiéramos señalar que, si bien en nuestro país está vigente la prestación por desempleo, ésta no incluye a las trabajadoras de casas particulares. En consecuencia, la pandemia evidenció la facilidad que tienen empleadores para despedir —a pesar de la prohibición de despidos_-, como veremos a continuación, dejando a las trabajadoras muchas veces sin algún tipo de ingreso.

El sector de trabajo doméstico se caracteriza por ser heterogéneo, compuesto por diversas tareas - según la normativa vigente se divide en cinco categorías ${ }^{13}$ - y modalidades. En cuanto a estas últimas, podemos distinguir entre quienes trabajan sin retiro/“cama adentro", en el caso de trabajadoras que conviven en el mismo hogar que sus empleadores, y quienes lo hacen con retiro, es decir, trabajadoras que residen en otro hogar. Los sueldos mínimos fijados para el sector por la Comisión Nacional de Trabajo en Casas Particulares (CNTCP) varían según categoría y modalidad. Es importante señalar que, si nos referimos al trabajo con retiro,

semanales, debe abonar voluntariamente la diferencia para llegar al aporte mínimo mensual y así acceder a la obra social. Sobre este punto, véase Poblete (2016).

${ }^{10}$ Cobro mensual por el embarazo desde las 12 semanas de gestación y hasta el nacimiento o interrupción del estado de embarazo.

11 Asignación para las trabajadoras registradas durante los 90 días de la licencia por maternidad y hasta los 270 días si su hijo o hija tiene síndrome de Down.

12 Asignación mensual para hasta cinco menores de 18 años o con discapacidad. La cobra sólo uno de los progenitores y se prioriza a la madre. La pueden percibir personas desocupadas, trabajadoras no registradas, trabajadoras de casas particulares, monotributistas sociales, entre otros.

${ }^{13}$ La Comisión Nacional de Trabajo en Casas Particulares establece las siguientes categorías: 1) Supervisor/a, 2) Personal para tareas específicas, 3) Casero/a, 4) Asistencia y cuidado de personas y 5) Personal para tareas generales. 
encontramos diversas situaciones: quienes trabajan fijas en un único hogar, quienes trabajan fijas en varios hogares y quienes lo hacen por hora a demanda, conocido en el mundo del trabajo informal como "changa". Esta heterogeneidad de modalidades permite entrever que algunas son más beneficiosas en cuanto a la posibilidad de formalizar la relación laboral o estabilidad, mientras que la modalidad por horas a demanda es la más inestable y portadora de las peores condiciones, porque no determina compromiso, obligación ni derechos laborales (Casas, 2019).

Asimismo, hay una dimensión que no se puede dejar de analizar cuando pensamos en el trabajo doméstico remunerado: las relaciones ambiguas que se generan. Mónica ${ }^{14}$, trabajadora doméstica y administradora de uno de los grupos de Facebook, señala:

Yo creo que recién ahora con lo que está pasando [pandemia] estamos siendo visibilizadas. Es un sector muy castigado el de nosotras y las mismas compañeras no se consideran trabajadoras. A veces caen en el engaño de creer que son parte de la familia y no es así. He trabajado con una compañera, quien estuvo 17 años con ellos, no registrada (por supuesto) (...). Ella dormía con las nenas, iban al campo, todo. Y bueno, cuando pasó el tiempo y nuestra empleadora se enfermó, las hijas la despidieron, sin pagarle un peso y sin recordar esos momentos, que ellos te hacen creer que vos sos parte de la familia. Y esas cosas duelen (...) porque yo lo viví con mis compañeras, te digo la verdad a mí me duele contarlo (entrevista a Mónica, 3 de junio de 2020).

En esta relación ambigua, como plantea Mónica, donde quienes te emplean "te hacen creer que sos parte de la familia", se torna particularmente significativa la categoría de lo doméstico planteada por Kofes (2001) y retomada por Gorban (2012); ya que permite salir de la contraposición entre lo público y lo privado para dar cuenta de relaciones que no son ni estrictamente familiares ni estrictamente laborales y que se constituyen como una interacción de clases desiguales.

\footnotetext{
${ }^{14}$ Los nombres que aparecen en este trabajo son reales en los casos en que las trabajadoras lo solicitaron; en otros, se han modificado respetando la confidencialidad. Ambas decisiones constituyen acuerdos realizados con las interlocutoras a lo largo del trabajo de campo.
} 
Para el análisis tomamos la noción de ambigüedad a partir de la propuesta de Débora Gorban (2012), para señalar el "tipo de relación que se establece entre empleadas y empleadoras, atravesada por la distancia social y la proximidad física y afectiva" (p. 34). Dicha relación supone, por un lado, la realización de tareas específicas de cuidado y atención que realizan las trabajadoras al interior de un hogar; y por el otro, que la relación requiere la contratación de alguien que realice esas tareas y conlleva el ingreso de una persona ajena al núcleo familiar. En particular, como señala la autora, significa el ingreso de una persona de los sectores más vulnerables e "infravalorados" de la sociedad y, agrega, más temidos por las clases más adineradas. Esta ambigüedad, que atraviesa el vínculo empleada-empleadora, no es ajena a las tensiones, encuentros, conflictos y silencios. $\mathrm{Y}$ en ese sentido, es posible que se generen situaciones de explotación, discriminación, violencia, que usualmente se encuentran invisibilizadas. Asimismo, a partir de esa convivencia "familiar y en aislamiento respecto a otras trabajadoras" se generan vínculos afectivos y personales entre la trabajadora y quien la contrata, éstos regulan de cierta forma la relación laboral, e influyen muchas veces de manera compleja en las condiciones de trabajo. Se configura una interacción de clases desiguales, permeada por una ambigüedad afectiva. En un trabajo anterior (Casas, 2019), se señala cómo en los relatos de las trabajadoras, el afecto y el compartir son aludidos constantemente. Por ejemplo, se evidenciaban situaciones en las que la trabajadora decidía continuar en un empleo por el hecho de "encariñarse" a pesar de recibir poca remuneración o de tener malas condiciones laborales, o situaciones en que mencionaba que se sentía "como de la familia". Sin embargo, en el fragmento de la entrevista con Mónica ella deja en claro que "ser cómo de la familia" lo considera un engaño, situación que evalúa como una barrera en el auto reconocimiento del sector "como trabajadoras". En definitiva, se plantea un escenario complejo, de relaciones ambiguas y que, en tanto trabajo de cuidado, supone una gran carga de subjetividad (Borderías, Carrasco y Torns, 2011). En consecuencia, si consideramos la relación laboral, la afectividad aparece en este tipo de trabajo como una variable que regula derechos y deberes de ambas partes (Canevaro, 2009b). En esta relación operan múltiples variables y se construye como un lugar de reciprocidad, jerarquía, códigos de clase, de género, generacionales y étnicos (Canevaro, 2009a; Gorban, 2012 y 2014; Cutuli y Pérez, 2011). Las características anteriormente mencionadas hacen que el sector de trabajo doméstico remunerado sea heterogéneo, complejo y estructuralmente desigual. Durante los primeros meses de pandemia, en los grupos de 
Facebook de trabajadoras se intercambiaba no sólo información sobre derechos laborales, la escala salarial o la resolución de conflictos, sino que a su vez se debatía y reflexionaba acerca de vivencias en torno al trabajo. Traemos aquí una reflexión que muestra la tensión en la relación laboral, potenciada en el contexto de crisis sanitaria, económica y social. Una usuaria publica en un grupo de Facebook: "Ahora somos una gran molestia para las jefecitas. ¿Por qué será? Antes nos amaban... ¿tan rápido se les acabó el amor?” (Registro de campo, 3 de julio de 2020). Ante esa pregunta, Dora, otra trabajadora doméstica, nos da esta respuesta: "Somos familia hasta que exigimos lo que nos corresponde. Cuando exigimos nuestros derechos, ahí empieza el problema" (entrevista a Dora, 29 de julio de 2020).

A continuación, mostraremos cómo el impacto de la crisis del COVID-19 ha agudizado aún más la situación en la que se encontraban las trabajadoras y ha incrementado tensiones en esta relación permeada por la desigualdad.

\section{Impacto negativo en la situación laboral del trabajo doméstico en el contexto de la pandemia por COVID-19 en Argentina}

“Cuando empezó la cuarentena mis patrones me despidieron” escribía una usuaria en uno de los grupos de Facebook de trabajadoras domésticas durante las primeras semanas del ASPO. Estos posteos se replicaban y traían una lluvia de comentarios de mujeres en las mismas situaciones. Era el preludio de un panorama que nos planteaba los siguientes interrogantes: ¿Cómo atraviesan el Aislamiento Social Preventivo y Obligatorio quienes viven de su trabajo cotidiano y no pueden trabajar? ¿Qué acontece con uno de los sectores que posee menos trabajadoras registradas? ¿En qué medida se cumple con los decretos relativos al pago de salarios y el aislamiento? Con este punto de partida decidimos hacer un relevamiento de la situación en que estaban las trabajadoras de casas particulares, por lo tanto, pensamos y elaboramos una encuesta online para conocer su situación laboral en el transcurso del ASPO. Misma que posteriormente profundizamos con entrevistas a trabajadoras domésticas remuneradas. Las entrevistas semiestructuradas fueron realizadas de manera virtual mediante el uso de la plataforma Zoom o a través de videollamadas de WhatsApp. Asimismo, hemos 
registrado y analizado diversas interacciones públicas en grupos de Facebook específicos para trabajadoras.

El trabajo de campo se realizó durante los meses más difíciles y dramáticos de la cuarentena en Argentina en término de restricciones de movilidad de personas. Esto nos planteó dos desafíos. Por un lado, el de realizar una investigación "sobre la marcha" y ante un panorama desconocido ${ }^{15}$.Y por el otro, llevarlo adelante en las condiciones de producción de conocimiento en que nos encontrábamos como investigadoras e investigadores en aislamiento en nuestros hogares ${ }^{16}$. ¿Cómo haríamos trabajo de campo si ya no podíamos hacer entrevistas cuerpo a cuerpo?; ¿cómo entrevistar entonces?; ¿cómo hacer observación participante sin "estar ahí"? Por tal motivo, tuvimos que innovar creando herramientas que hasta ese momento desconocíamos, en particular, y han sido poco exploradas para la investigación en general. Este proceso claramente contó con una potencialidad, dado que registramos en "tiempo real" experiencias, vivencias y consecuencias atravesadas por la situación inesperada de una pandemia. Es así como adaptándonos a la nueva realidad, fuimos encontrando en el uso de las tecnologías digitales una modalidad de construcción del trabajo de campo donde la virtualidad se constituye como una herramienta de gran importancia. Desde el aislamiento, se nos abría la oportunidad de generar investigaciones que dieran cuenta — en el momento - de lo que se estaba viviendo, e implicaban indefectiblemente la virtualidad (Capogrossi, Magallanes y Socaire, 2015). Además, siguiendo a Ardèvol, Estalella y Domínguez (2008), la virtualidad no es únicamente un instrumento para interpretar esa realidad, sino también un espacio que media la relación entre los sujetos, y entre estos y quienes investigamos: "La tecnología media en la relación de nuestros informantes con el mundo, y el conocimiento sobre el mundo que un antropólogo genera está también mediado por la tecnología que utiliza en su práctica etnográfica" (p. 12).

\footnotetext{
${ }^{15}$ En ese sentido, quisiéramos destacar que esta investigación se enmarcó en un contexto en que las ciencias sociales cambiaron sus agendas para abordar y analizar en tiempo real los impactos y las consecuencias de la crisis del COVID-19 en sus múltiples dimensiones de la vida social. Entre otros trabajos, podemos mencionar: Claudia Figari (2020), Instituto de Estudios Sociales en Contexto de Desigualdades (2020).

${ }^{16}$ Este novedoso contexto de producción académica representó una doble carga, ya que en los espacios de trabajo/hogares se agregaron tareas domésticas y de cuidado.
} 
Una vez diseñada la encuesta la difundimos, entre el 13 de abril y el 10 de mayo, mediante redes sociales - principalmente grupos de Facebook - y también de WhatsApp tanto a investigadoras e investigadores como a las trabajadoras a las que les interesó la propuesta. La encuesta consta de un cuestionario anónimo autoadministrado por medio de una plataforma online, estructurada con base en preguntas cerradas y abiertas, con un ítem de campo abierto a comentarios. Este campo abierto resultó un rico espacio de indagación y nos permitió detectar otras situaciones que no habíamos previsto. Cabe aclarar que durante el período en que llevamos adelante la encuesta, la excepción de la categoría de cuidado y la prohibición de trabajar en casas particulares en el resto de las categorías eran las mismas para todo el territorio nacional. Durante esa fecha se obtuvieron 635 cuestionarios válidos, respondidos casi en su totalidad por mujeres $(99.4 \%)$.

Cabe señalar, también, que esta innovación tuvo su contrapartida en la aparición de nuevos obstáculos: en primer lugar, vale objetivar el carácter no estadístico del cuestionario realizado, éste no contó con un método de muestreo probabilístico de selección aleatoria. El cuestionario se desarrolló mediante un método de "bola de nieve"17 tanto en redes sociales como por WhatsApp, que al menos demandó un conocimiento - y seguramente un sesgo- de utilización de uso de plataformas de autocompletado y aplicación de una tecnología - muy extendidade smartphone. En cuanto a los principales espacios de difusión de la encuesta, particularmente de los dos grupos de trabajadoras domésticas en Facebook en los que participamos habitualmente, uno de ellos posee cuarenta y nueve mil miembros (al momento de la encuesta tenía alrededor de quince mil) y el otro tres mil novecientos. Se trata de grupos masivos con la participación de usuarias de todo el país. Las interacciones diarias de estos grupos van desde consultas sobre salario, derechos laborales o situaciones de despido hasta posteos que comparten experiencias del trabajo ${ }^{18}$. Tanto las interacciones como quienes ingresan a los grupos están supervisadas por administradoras, que pueden eliminar publicaciones que no se limitan a la temática de éste. La encuesta fue compartida en aquellos grupos tanto por quienes

\footnotetext{
${ }^{17}$ El muestreo de "bola de nieve" es un tipo de muestreo no probabilístico que se utiliza cuando los sujetos de la investigación son difíciles de encontrar. En este tipo de muestreo los participantes de una investigación "reclutan" a otros participantes para una prueba o estudio. Aquí los investigadores usan el propio juicio de los participantes para acceder a otros sujetos.

${ }^{18}$ Este ámbito de interacción y sus implicancias metodológicas en la investigación es un punto que quisiéramos desarrollar en profundidad en posteriores publicaciones.
} 
la realizamos como por otras trabajadoras que conocimos mediante la red social en cuestión. Además, si bien la encuesta se basó en el anonimato de quienes respondían, hicimos un seguimiento detallado de todas las respuestas donde las encuestadas debían consignar las tareas que realizaban al momento de ésta. A su vez, el campo abierto de la encuesta permitió que contaran sus situaciones particulares y con ello monitorear si algunos de los formularios eran completados por personas ajenas a la actividad. Por último, sobre este punto vale aclarar que los datos recabados por la encuesta fueron luego indagados y analizados junto con trabajadoras domésticas en las entrevistas realizadas.

Siguiendo con los obstáculos, respecto a las entrevistas, podemos señalar una vez más lo novedoso de las tecnologías de la información. Tal como plantea irónicamente Christine Hine: "Los etnógrafos de Internet, en vez de ensuciar sus despachos con tierra y polvo de lugares lejanos, pueden llegar a desgastar el escudo universitario de tapiz de sus sillas" (2004, p. 60). Aquí se plantea una nueva problemática —que no se resolverá en este artículo- que es en cierta forma el abandono momentáneo de la tradicional manera de realizar entrevistas a partir de la interacción cara a cara. En una entrevista a través de una videollamada se abren nuevas disyuntivas alrededor de los efectos de la mediación tecnológica, cambiando el sentido del tiempo y el espacio. Se recrea un nuevo contexto de la entrevista desde el montaje realizado a través de la cámara, hasta la estética que se decide mostrar. Claramente la inmersión en el campo se ve fuertemente modificada. No obstante, el quehacer antropológico se ha enfrentado desde siempre a diversos retos y hechos inesperados que ocurren en el trabajo de campo. Lejos de sugerir renunciar al enfoque etnográfico, planteamos la posibilidad de explorar nuevas herramientas e innovar de manera creativa y estratégica los contextos inéditos propios del trabajo de campo.

Por lo planteado hasta aquí, privilegiamos una estrategia metodológica (Achili, 2005; Guber, 2001) que apunta a iluminar la diversidad de situaciones y prácticas desarrolladas por los sujetos sociales, en tanto que implican sentidos respecto de las condiciones en las que los sujetos desarrollan su vida. En los siguientes subapartados mostramos, por un lado, las características sociodemográficas y laborales de las personas que respondieron la encuesta y, por el otro, los principales hallazgos referidos al impacto negativo de la pandemia en el sector. 


\section{Características sociodemográficas y laborales de las trabajadoras que respondieron la encuesta}

La mayor parte de quienes respondieron la encuesta reside en la Provincia de Buenos Aires (67.2\%) y en la Ciudad Autónoma de Buenos Aires (11.2\%). El 7.9\% vive en la Región Noroeste (Jujuy, Salta, Tucumán y Santiago del Estero); el 5.8\% en la Región Pampeana (Córdoba, Entre Ríos, La Pampa y Santa Fe); el 3.6\% en la Región de Cuyo (Mendoza, San Luis y San Juan); el $2.7 \%$ en la Región Noreste (Formosa, Chaco, Corrientes y Misiones) y el $1.6 \%$ en la Región Patagónica (Chubut, Neuquén, Río Negro). En cuanto a las edades de las encuestadas, la franja etaria es de 20 a 71 años, aunque la mayoría se ubica entre los 40 y los 49 años (37.8\%), y entre los 30 y los 39 años (27.4 por ciento).

Dentro de las preguntas, dos ítems indagaban si la persona encuestada tenía descendencia en edad escolar o pertenecía a grupos considerados de riesgo, ya que ambas situaciones significaban que estaba en condiciones de solicitar una "licencia con goce de sueldo", aun si pertenecía a la cuarta categoría (considerada esencial). Frente a la pregunta por hijas e hijos a cargo, el $85.5 \%$ respondió tenerlos —el $63.1 \%$ está en edad escolar ${ }^{19}$ - y un $68.7 \%$ dijo no pertenecer a ningún grupo de riesgo en relación con el COVID-19 ${ }^{20}$. Es preciso señalar que el peso de la responsabilidad por los cuidados de hijas, hijos o personas a cargo entra en tensión con el trabajo por el riesgo de contagiarse o de perder la fuente de ingresos, tal como señala una trabajadora doméstica de la Provincia de Buenos Aires:

Yo tengo un hijo de 11 años que tiene problemas respiratorios y alergias por los cambios de clima. Estoy desesperada porque si se levanta la cuarentena tengo que ir a trabajar, porque soy madre soltera. Y lo tengo que dejar con una señora

\footnotetext{
${ }^{19}$ El 16 de marzo, dada la suspensión de clases por la pandemia en Argentina, el Ministerio de Trabajo, Empleo y Seguridad Social publicó la Resolución núm. 207/2020 que estableció una licencia con goce de sueldo a "progenitor, progenitora, o persona adulta responsable a cargo, cuya presencia en el hogar resulte indispensable para el cuidado del niño, niña o adolescente" (Art. 3).

${ }^{20} \mathrm{La}$ misma resolución (Número 207/2020) establece una licencia a personas mayores de 60 años (excepto que sean "personal esencial para el adecuado funcionamiento del establecimiento" o personal de salud), embarazadas o pertenecientes a grupos de riesgo (Art.1). Según el Ministerio de Salud de la Nación se considera grupo de riesgo a quienes tienen más de 60 años, a embarazadas, personas con enfermedades respiratorias, cardiovasculares, inmunosuprimidas y con afecciones como diabetes o insuficiencia renal crónica.
} 
que viene a cuidarlo. Y no sé qué hacer, porque si pierdo mi trabajo a él le va a faltar, pero si voy a trabajar lo puedo enfermar y no tenemos obra social ni tengo apoyo del padre (comentario en campo abierto de la encuesta, 18 de abril de 2020).

Por otro lado, acerca de las modalidades del trabajo doméstico que realizan quienes respondieron la encuesta, encontramos que un 55\% trabaja con retiro en un único hogar, el 32\% trabaja con retiro en varios hogares, un $8 \%$ trabaja sin retiro y el 5\% con otro tipo de modalidad. En cuanto al tipo de actividades, las principales — el 65.8\% — son las generales (de limpieza y otras tareas del hogar) y el $22 \%$ combina tareas de limpieza y de cuidado de personas. En menor medida, el 8.5\% contestó que realiza exclusivamente tareas de asistencia y de cuidado de personas, y el 4\% remanente desarrolla otro tipo de actividades. En lo referente a la cantidad de horas dedicadas a la jornada laboral, un poco más de la mitad respondió trabajar entre cuatro y ocho horas (el 56\%), mientras que el 26\% trabaja más de ocho horas y únicamente el 18\% lo hace entre una y cuatro horas.

En lo que respecta a la fuente de ingresos monetarios en los hogares de las trabajadoras que respondieron la encuesta, cerca de la mitad - el 46.6\% - no tiene ningún ingreso extra por fuera de lo que cobra por su empleo y el 53.4\% tiene otro ingreso (o varios) además del que le proporciona su trabajo. Sobre este último punto, se destaca la Asignación Universal por Hijo (AUH) - y en menor medida otro beneficio social — que recibe el 28\% de las trabajadoras. Un $18.9 \%$ cuenta también con el ingreso de su pareja o familiar, un 4.7\% recibe jubilación o pensión y un $4.2 \%$ obtiene ingresos por otro trabajo extra. En este punto, resulta significativa la cantidad de trabajadoras que no poseen otro tipo de ingreso además del proporcionado por su trabajo en casas particulares, y en ese sentido se advierte que cualquier modificación en sus condiciones laborales — reducción de sueldo o de la jornada laboral, pago en cuotas, despido, etcétera- implica una situación crítica para ellas.

En cuanto el acceso a derechos laborales y el grado de formalización, un $60.2 \%$ de las trabajadoras que respondieron la encuesta indicó estar registrada, el 14.8\% dijo estar registrada 
en algunos hogares y en otros no, mientras que el $25 \%$ contestó no estarlo ${ }^{21}$. Acerca del acceso a los servicios de salud, el $64.1 \%$ concurre a hospitales públicos o a salas de atención primaria, mientras que el 30.7\% utiliza los servicios a través de alguna obra social, el 1.7\% acude a servicios de atención privada a través de una prepaga y el resto indicó “otro". Para quienes están en condiciones de informalidad o registradas en algún hogar y en otros no, el acceso a una obra social se dificulta, tal como expresa una trabajadora de la provincia de Córdoba: "Esta situación es muy dura para quien se gana el dinero día a día, yo me hago el sueldo día a día trabajando en varias casas (mañana y tarde) al no tener un sueldo fijo y además sin obra social" (comentario en campo abierto de la encuesta, 22 de abril de 2020).

López Mourelo (2020) señala que entre las trabajadoras domésticas no registradas sólo un 9.4\% tiene acceso a una obra social: "Si bien Argentina cuenta con un sistema de salud público universal, casi 950,000 trabajadoras no cuentan con la cobertura de salud que les permitiría tener acceso a un servicio de atención de mayor calidad si llegaran a enfermarse" (p. 16). En efecto, en el contexto de la emergencia sanitaria causada por la pandemia del CovID-19, la falta de acceso a servicios de salud se agrava y constituye un riesgo doble para el sector.

Por último, respecto del grado de sindicalización de las trabajadoras que respondieron la encuesta, el $88 \%$ no está afiliado a algún sindicato mientras únicamente el 12\% lo está. Estos datos resultan importantes al momento de analizar la situación de precarización de este sector del trabajo.

\section{Principales hallazgos de la encuesta}

En primer lugar, preguntamos quiénes estaban asistiendo a sus lugares de trabajo y quiénes no. En las fechas en que se realizó la encuesta — entre el 13 de abril y el 10 de mayo- el 82.2\% de las trabajadoras respondió no estar concurriendo a su lugar de trabajo, en tanto el 17.8\%

\footnotetext{
${ }^{21}$ Cabe destacar que la tasa de formalidad de las personas que respondieron la encuesta es bastante más alta que la que se registra en datos oficiales citados anteriormente: el 76.8\% de trabajadoras domésticas está en la informalidad en Argentina.
} 
estaba yendo. A su vez, entre quienes no asistían a trabajar, el 3.6\% habían sido despedidas cuando se decretó la cuarentena obligatoria.

Como señalamos anteriormente, las personas que fueron exceptuadas del ASPO y asistieron a trabajar, son aquellas que desarrollaban tareas de asistencia y cuidado. Sin embargo, la encuesta reflejó que varias de las trabajadoras que concurrían a trabajar no desempeñaban estas tareas específicas. A saber, sólo un 3.4\% lo hacía. Del resto de quienes fueron a trabajar durante el ASPO, un 6.4\% combinaba actividades de cuidado con tareas de limpieza, un 6.9\% únicamente realizaba tareas de limpieza y el $0.9 \%$ otro tipo de actividades, consideradas no esenciales. Quiere decir que los empleadores no respetaron el derecho de la trabajadora de no asistir y cobrar igual. Sobre esto, logramos identificar una de las estrategias que utilizaron: el cambio de categoría $^{22}$ de las trabajadoras de limpieza y tareas generales — categoría 5- a la categoría 4 de cuidados y asistencia. Esto permitía que pudieran tramitar el permiso de circulación ${ }^{23}$ como trabajadora esencial. Nos encontramos con que un 3.6\% de quienes respondieron la encuesta manifestó que sus empleadores le cambiaron la categoría durante la cuarentena. Acerca de esta situación reflexiona una trabajadora de la Ciudad de Buenos Aires, que realiza tareas de cuidado y limpieza y que continuaba asistiendo a su trabajo:

Debería ser muy claro que no se puede cambiar de categoría por conveniencia del empleador. Multarlos y, ya que cambia de categoría, que paguen más. Es muy injusto. Otra cosa, cuando dicen convenir con el empleador ellos nunca te van a decir "quedate en casa". Estoy poniendo en riesgo mi vida. Pido un plus para las que salimos a arriesgar nuestra vida (comentario en campo abierto de la encuesta, 16 de abril de 2020).

\footnotetext{
${ }^{22}$ Corresponde a las categorías profesionales estipuladas por la Comisión Nacional de Trabajo En Casas Particulares, que de acuerdo con tipos y modalidades son fijadas dentro de una escala salarial.

23 El permiso se tramita a través de la aplicación para celulares "CuidAR" o en la página web https://www.argentina.gob.ar/circular/tramite. El primer paso del trámite consiste en seleccionar algunas opciones por las cuales estás realizando el trámite y luego completar una declaración jurada consignando datos personales, datos de contacto y domicilio personal, datos de transporte a usar, datos de las personas a asistir o trasladar y una declaración jurada de salud.
} 
Como expresa la trabajadora en el fragmento anterior, el contexto de pandemia y el creciente número de casos por transmisión comunitaria representan un gran riesgo para quienes concurren a su lugar de trabajo. Ir es "arriesgar la vida". No sólo por el hecho de tener contacto con otras personas sino por lo que implica el traslado en transporte público, uno de los principales focos de contagio. En la encuesta identificamos que, entre quienes asisten a trabajar, un 50.9\% viaja en transporte público y casi el mismo porcentaje afirma que en sus lugares de trabajo no le proveen elementos de protección (guantes, barbijos, alcohol en gel). Este panorama indica una tensión entre el trabajo y el riesgo, que cobra especial atención si tenemos en cuenta que las tareas de cuidado han sido declaradas actividad esencial. "Arriesgar la vida" ¿a cambio de qué?: "Quienes trabajamos durante el COVID-19 arriesgando nuestra salud y nuestra vida merecemos un mejor salario, y no cobrar solo $18600^{24}$ pesos cuando de nosotras depende el cuidado de personas" (comentario en campo abierto de la encuesta, 30 de abril de 2020).

Relatos como éste plantean, entonces, una paradoja: el cuidado y la asistencia de personas es considerada una actividad esencial, pero se siguen manteniendo las mismas $\longrightarrow$ peorescondiciones de precariedad y bajos salarios. Es decir, no se obtiene ninguna compensación económica ni tampoco, como veremos en el apartado siguiente, un reconocimiento social. Y se genera un riesgo mayor de exposición al virus. A esta situación se suma que las cargas de cuidado en el contexto de pandemia se han redoblado. Como mencionamos anteriormente, muchas trabajadoras tienen descendencia en edad escolar y el hecho de que las instituciones educativas estén cerradas repercute en la cotidianidad de las familias, cuyos miembros deben continuar trabajando ya sea en el lugar al que concurren, como es el caso citado, o desde sus hogares.

En lo que respecta a las personas que no asisten a trabajar, el 78\% afirmó que la decisión de respetar el ASPO fue acatada de manera conjunta con sus empleadores, aunque esto, es preciso subrayar, no significa que cumplieran con el pago del salario. Luego, el 11.6\%, de quienes no van a trabajar, decidió no asistir a pesar de que sus empleadores le pidieron que concurriera de todos modos. Y, como ya señalamos, el 3.6\% de las trabajadoras señaló que fue despedida durante el aislamiento. Por último, el $6.9 \%$ dice que no concurre por otros motivos,

\footnotetext{
${ }^{24}$ Tomando el valor del dólar oficial en Argentina, para el 30 de abril del 2020, el monto sería 270.55 dólares.
} 
principalmente porque no le pagan o no sabe/no le informaron si le pagarán. El panorama incierto se mezcla con las condiciones de precariedad del sector, donde la posibilidad de perder el trabajo pende de un hilo. En ese sentido, en los dos fragmentos que mostramos a continuación se observa cuán complejo es respetar el aislamiento cuando peligran el ingreso o la fuente de trabajo: "No sé si yo estoy actuando bien al no ir a trabajar. Temo perder mi trabajo por esto" (comentario en campo abierto de la encuesta, 18 de abril de 2020). "Cuando empezó el aislamiento dejé de ir a trabajar, pero quiero volver ya que recién hacía un mes que había empezado. No quiero perder mi fuente de trabajo" (comentario en campo abierto de la encuesta, 30 de abril de 2020).

En segundo lugar, a partir del análisis de los fragmentos anteriores, advertimos que los efectos de la crisis por la pandemia del COVID-19 sobre los ingresos y la situación de precariedad laboral impactaron de manera significativa en la vida de las trabajadoras domésticas encuestadas. A saber, entre cinco y seis de cada 10 trabajadoras —un 55.9\% — vieron empeorada su situación laboral desde que se decretó el ASPO. Dentro de las situaciones que podemos mencionar, encontramos que un $3.6 \%$ sufrió un despido, a un $20.2 \%$ sus empleadores no le pagan su salario, a un $13.1 \%$ le redujeron el salario respecto del mes anterior, un $7 \%$ no tenía conocimiento sobre si le iban a abonar el salario y un $6.6 \%$ - trabajadoras en varios hogares-manifestó que en algunos le abonaban y en otros no. Sólo al 33.1\% de las trabajadoras que completaron la encuesta le continuaban pagando durante el ASPO, aunque no prestara servicios y al $11 \%$ le continuaban pagando porque concurría a trabajar. 


\section{Gráfico 1: Situación laboral entre el 13 de abril y 10 de mayo de las trabajadoras domésticas durante el ASPO en Argentina}

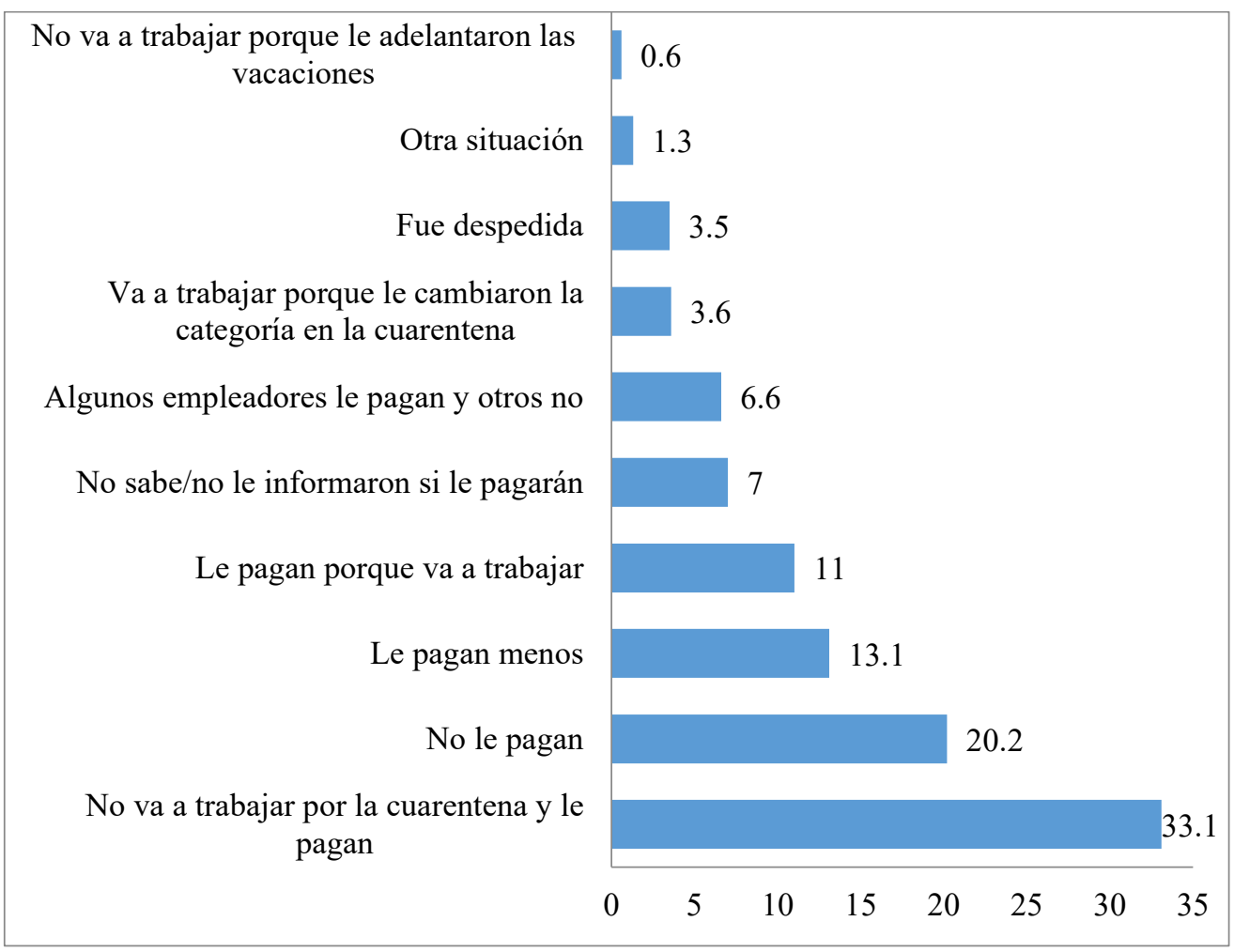

Fuente: Encuesta a trabajadoras de casas particulares sobre su situación laboral en el contexto de aislamiento por la pandemia de COVID-19 en Argentina

El impacto negativo en la situación laboral de las trabajadoras domésticas, relevado en la encuesta, es una foto de los primeros meses del ASPO en Argentina. Según el informe "Situación y evolución del trabajo registrado (Julio 2020)" del Ministerio de Trabajo, Empleo y Seguridad Social de la Nación, si se comparan los meses de abril en los años 2019 y 2020, durante la pandemia se dieron de baja del registro a 19600 trabajadoras de casas particulares ${ }^{25}$. Asimismo, en los relatos de las mujeres que respondieron la encuesta encontramos constantes alusiones a la incertidumbre y al miedo de perder el trabajo, ante la posibilidad de la extensión del ASPO. Es decir, un escenario abierto si la situación se agravase aún más, tal como comenta una trabajadora de la Ciudad Autónoma de Buenos Aires: “Así como estamos cumpliendo con la cuarentena, también tenemos la incertidumbre de no saber hasta cuándo sea todo esto. En mi

${ }^{25}$ Ministerio de Trabajo, Empleo y Seguridad Social (2020). 
caso no sé hasta cuándo mi empleador podrá pagarme el sueldo, ya que es monotributista" (comentario en campo abierto de la encuesta, 15 de abril de 2020).

En tercer lugar, indagamos en el conocimiento de derechos laborales en este contexto y las medidas tomadas por el gobierno nacional. En cuanto a las disposiciones mencionadas en el decreto que estableció el ASPO y la excepción de actividades esenciales, un $82.8 \%$ de las trabajadoras que completaron la encuesta estaba al tanto de su derecho a no asistir a su trabajo mientras estuviera inhabilitada la actividad y sabía que sus empleadores debían abonarle su salario de todas maneras. Sin embargo, un 10\% señalaba que no tenía información confiable sobre sus derechos y el $6.5 \%$ directamente los desconocía. Sobre este punto, preguntamos acerca de los medios por los cuales se habían informado acerca de la situación del sector. Un $59.6 \%$ dijo enterarse a través de los medios de comunicación (radio, tv, internet), un 13.8\% por medio de algún sindicato, el $10.1 \%$ por amistades y familiares, el $9.9 \%$ por sus empleadores y un $6.7 \%$ por otras vías.

Por último, respecto de las medidas de mitigación económica de la pandemia y las de aislamiento, indagamos en la recepción del Ingreso Familiar de Emergencia (IFE) ${ }^{26}$, una prestación de emergencia que - como indicamos en la nota al pie núm. 3- está destinada a personas que se encuentren desocupadas o que trabajen en informalidad, sean monotributistas o trabajadoras de casas particulares. En el período en que realizamos la encuesta, el bono se encontraba en su primer pago. Un 55.7\% de trabajadoras cobró el primer IFE otorgado por el gobierno nacional y el 15\% no tenía conocimiento de cómo tramitarlo. Queremos señalar que otra de las estrategias que detectamos por parte de los empleadores consistió, en algunos casos, en descontarles a las trabajadoras de su salario mensual el monto que iban a cobrar a través del IFE. Como cuenta una trabajadora de la provincia de Salta: "Me dijeron que me iban a reducir el sueldo al 50\% porque estaban en crisis por la pandemia (...). La mayoría pone como escudo el bono que decidió dar el presidente" (comentario en campo abierto de la encuesta, 18 de abril de 2020).

\footnotetext{
${ }^{26}$ Según la Administración Nacional de la Seguridad Social (ANSES), fue la prestación de mayor alcance en la historia argentina: llegó al 20\% de la población del país. Y un 2.1\% de las personas que lo recibieron es trabajadora doméstica remunerada.
} 
Por todo lo expuesto anteriormente, se evidencia un impacto negativo en las condiciones laborales y de vida de las trabajadoras domésticas. En otras palabras, la pandemia vino a echar luz sobre las desigualdades y condiciones de vulnerabilidad que existían previamente, profundizándolas. Así lo relata Marcela Muñoz — secretaria de Asuntos Laborales del Sindicato de Empleadas en Casas de Familias de Entre Ríos (SECFER) — en un texto titulado "Las Juanitas y la pandemia", que nos envió en los meses en los que realizamos esta investigación. Allí reflexiona a partir de un caso que circuló por las redes sociales al comienzo del ASPO ${ }^{27}$. Se trata de una mujer famosa que se filma con su empleada doméstica, Juana, y dice a la cámara: "Juanita se quedó encerrada acá en la casa". Luego de preguntarle a ella por qué se había quedado, ante una respuesta tímida de su empleada, la famosa la interrumpe y agrega: "Que no se entere Alberto [el presidente de Argentina]". En su texto, Marcela escribió:

Empleadores que no consideran a su trabajadora un ser independiente atado a las leyes de una sociedad, el DNU [decreto] también era para ellos (empleadores) y las Juanitas volver a su casa con sus seres queridos y tener derecho a que se le pague su sueldo completo sin descuento. El derecho de las Juanitas que trabajan en casa de familia cama adentro las cuales parecieran no tener horas ni vida propia.

En la pandemia salió a flote la situación de 70 por ciento de trabajadoras no registradas, la desvalorización de la tan llamada cadena de cuidado, tan importante para la vida, pero tan poco valorada en la escala salarial.

Donde \#QuedateEnCasa ${ }^{28}$, hoy más que nunca es la cara de una deuda a este sector de trabajadoras, mujeres y madres que tiene que elegir entre el bienestar de otros, ni más ni menos por un plato de comida para los suyos".

(Fragmento del texto "Las Juanitas y la pandemia" de Marcela Muñoz, publicado en el muro de Facebook de @Sindicatoempledasencasasdefamilias, 3 de junio de 2020 [El resaltado es nuestro]).

\footnotetext{
${ }^{27}$ Telenueve. (24 de marzo de 2020).

${ }^{28}$ El Hashtag \#QuedateEnCasa es utilizado en diversas redes sociales para expresar la necesidad de que la población se aísle en sus hogares, en la medida de sus posibilidades, ante el avance de la pandemia.
} 
El fragmento seleccionado, elocuente, condensa una multiplicidad de cuestiones fundamentales del trabajo doméstico remunerado y el contexto de pandemia. Por un lado, muestra la disputa que subyace en cuestión de materia laboral, expresada en la recurrencia de la palabra "derecho". Una idea que transita todo el fragmento seleccionado haciendo evidente la situación de precarización estructural del sector. Por el otro, se puntualizan diversas estrategias de los empleadores durante la cuarentena, que hemos mencionado dentro de los principales hallazgos de la encuesta: cambios de categorías, disminución de horas de trabajo, disminución del salario, enojos, incluyendo amenazas de toda índole. Asimismo, tal como hemos observado en la encuesta, el relato da cuenta de la práctica de empleadores de hacer pasar el Ingreso Familiar de Emergencia que el Estado nacional ejecutó como política de contención, como si fuese el salario. Por último, queremos subrayar los sentidos que se desprenden de este relato: la idea de las "Juanitas" es una expresión que va más allá del caso puntual que se hizo público y le pone nombre propio al "sentido común". Las "Juanitas" responde a un imaginario de mujer trabajadora, madre y humilde, en magras condiciones laborales, que "tiene que elegir entre el bienestar de otros, ni más ni menos por un plato de comida para los suyos". Las Juanitas son aquellas mujeres que, frente al reclamo patronal sintetizado en la frase: “¿qué más quieren?”, no levantan la mirada para conservar su fuente laboral. Finalmente, y dando lugar al apartado siguiente, el fragmento manifiesta con nitidez y claridad asombrosas cómo el contexto de pandemia construye un discurso que desvaloriza la tarea fundamental que es el trabajo de cuidado.

\section{El discurso pandémico del año 2020: Dar "batalla al enemigo invisible"}

En distintos medios de comunicación de Argentina se habla del "enemigo invisible" cuando se trata de abordar el tema del COVID-19, o se comparan las políticas de contención de los contagios con una guerra. Del mismo modo, el gobierno argentino alude comúnmente a la guerra contra el virus o a los "soldados de las primeras trincheras", como denomina al personal del sistema de salud. Se ha instalado un sentido común — no sólo en Argentina- que nombra indistintamente la pandemia del coronavirus con analogías y metáforas bélicas, produciendo y 
reproduciendo la idea literal de que se libra una batalla contra un "enemigo invisible"29. Este "enemigo invisible" afectaría a "todos (y todas) por igual", reproduciendo una mirada biologicista - propia del modelo médico hegemónico (Menéndez, 1988) - que no da cuenta de las desigualdades sociales y los impactos diferenciales en la sociedad. Por otra parte, estamos viviendo a toda hora en los medios de comunicación un desmesurado discurso "de las cifras": se contabilizan los contagios, los recuperados y los decesos con una sobresaturación de “expertos" - mayoritariamente virólogos - que, desde un relato científico, realizan diversas recomendaciones para sobrellevar este momento. Estos discursos se fundan sobre un potente sentido acerca de la producción de la masculinidad y el tecnicismo científico.

Joan Scott (2008) argumentó que las tramas de sentido en las que se entrelazan la masculinidad y la feminidad como categorías opuestas, binarias y jerarquizadas constituyen las formas simbólicas de poder más resistentes, recurrentes y arraigadas en nuestras sociedades occidentales. Reafirmando esta idea, Connell (1997) y Bourdieu (2012) coinciden en que todo conocimiento es una operación fundamental de división de dos universos opuestos: lo femenino y lo masculino. Estas tramas de relaciones de significación orientan las construcciones de toda práctica social en nuestras sociedades occidentales organizadas bajo el modo de producción capitalista. Un rasgo interesante de los discursos mencionados consiste en producir y consolidar una "hoja de ruta", un repertorio de prácticas y representaciones que integran los contornos de una fuerte manufactura de la masculinidad. Es más, aquí no se trata estrictamente de la relación entre hombres y mujeres, sino de la relación entre los significantes femeninos y masculinos en la construcción de sentidos acerca de la pandemia. La noción de guerra impone un relato viril de exaltación del "heroísmo", de la "gloria", al tiempo que produce y reproduce la "épica" en aquellas y aquellos que mueren en la "guerra contra el enemigo invisible". Se fortalece así lo que podemos llamar experiencia de la masculinidad heroica ${ }^{30}$ (Palermo, 2017). Asimismo, se profundiza la imagen de un mundo en riesgo, donde toda/o "otra/o" representa un potencial

\footnotetext{
${ }^{29}$ Rodríguez Yebra, Martín. (28 de marzo de 2020); Infobae. (21 de abril de 2020); Rubinstein, Adolfo. (17 de mayo de 2020).

${ }^{30}$ Este concepto lo hemos utilizado para analizar las experiencias obreras de la etapa estatal de la empresa YPF. Nos permitió dar cuenta de un relato producido desde la empresa, que se asentó sobre tres pilares fundamentales: la asimilación del trabajo petrolero al progreso de la nación/patria, la consolidación en términos simbólicos de la idea de sacrificio y entrega y, por último, una particular noción acerca de la muerte en el ejercicio del trabajo (Palermo, 2017, p. 36). Con las precauciones debidas, creemos que esta conceptualización nos permite iluminar parte de los sentidos que hoy se reflejan en el contexto de la pandemia del COVID-19.
} 
peligro para la propia vida. Se promueve, reafirmando la centralidad masculina, la experiencia de un contexto peligroso, ligado a la tarea humana de protección y administración.

En este marco: ¿qué sucede con las prácticas y representaciones femeninas? ¿Y qué acontece con aquellas tareas "naturalmente" conceptualizadas como femeninas? Sin duda, en esta (a)normalidad pandémica, se hace más fuerte un mundo social hostil para la expresión de los significantes femeninos. Las trabajadoras de casas particulares ejercen de por sí un trabajo puertas adentro, en un territorio nebuloso —el ámbito de lo doméstico- para el alcance del control del Estado; en ese territorio donde se entremezclan profundamente afectividades y relaciones laborales. En el ámbito de lo doméstico se desarrolla un valioso trabajo que, al contrario del discurso pandémico, no se inscribe en un relato de masculinidad heroica: no hay gloria ni épica en esta labor. En contraste, las tareas de trabajo doméstico expresan significantes "naturalmente" femeninos, asociados con el tacto, la delicadeza y el cuidado. También se alejan de procedimientos técnico-científicos, ya que este tipo de actividades son consideradas de baja calificación.

Norma Fuller (1997) llama lo abyecto al negativo contra el cual se diseña la producción de la masculinidad. En nuestro caso, las tareas de trabajo doméstico se configuran como lo abyecto frente al discurso pandémico del CoviD-19. Para lo abyecto se reservan todo tipo de hechos que acrecientan las tramas de la violencia. Durante la cuarentena, hemos revisado distintas situaciones por las que pasaron las trabajadoras de casas particulares, que realizan una labor desvalorizada e invisible (Gorban, 2014; Capogrossi, 2020), que incluso puede pensarse como descartable. Algunos relatos dibujan lo expresado: "Mi situación particular es que fui despedida en cuanto empezó la cuarentena obligatoria de uno de los trabajos fijos que tenía. En los otros directamente no responden o no se hacen cargo porque no trabajaba con registro. En síntesis, estoy desempleada y sin ningún ingreso" (comentario en campo abierto de la encuesta, 15 de abril de 2020). "Una de mis empleadoras me envió un correo electrónico para decirme que al final de la cuarentena no iba a precisarme más y tampoco podría pagarme abril" (comentario en campo abierto de la encuesta, 17 de abril de 2020). 
Por otro lado, el contexto y sus discursos hegemónicos reflejan un escenario de miedo e incertidumbre que adquiere representaciones diversas. En la sociedad —en términos generales - el temor al contagio del coronavirus se hace patente en cada interacción. Entre las trabajadoras de casas particulares, esto pasa a un segundo plano dando lugar a un miedo distinto: el de "perder el trabajo", la incertidumbre laboral. Una trabajadora de la Provincia de Buenos Aires relata:

Mis empleadores me abonan aún, aunque temo que no lo hagan más. La verdad es que estoy muy asustada por lo que puede pasar. Me preocupa mi vuelta al trabajo porque soy mamá soltera y único sostén de mi hija. Yo hace dos años (para tres) y sigo en negro. Y cuando reclamo algo, como por ejemplo el aguinaldo, me dijeron que no me correspondía. Y por no perder mi trabajo me quedé callada (comentario en campo abierto de la encuesta, 15 de abril de 2020).

En un contexto aciago, donde reinan las dudas antes que las certezas, los discursos que predominan en torno a la pandemia confluyen hacia la significación de la preeminencia masculina que normalizan un proceso de negociación asimétrica, frente a la (des)legitimidad de las tareas y representaciones abyectas.

\section{Reflexiones finales:}

\section{La paradoja de un trabajo esencial y desvalorizado}

En el presente trabajo, pudimos analizar en tiempo real los efectos y consecuencias de la pandemia del COVID-19 en el sector de las trabajadoras domésticas. Intentamos caminar el andarivel — nada sencillo- de producir investigación científica en ese contexto, con el obstáculo de la no presencialidad y las condiciones de producción de quienes investigábamos. No obstante, lo que en un principio significó una dificultad insalvable se fue convirtiendo en una posibilidad nueva: elaboramos una encuesta virtual que arrojó datos de sumo interés, al punto de tener un impacto en medios públicos de comunicación que hoy nos sigue 
sorprendiendo ${ }^{31}$. Al mismo tiempo, la virtualidad nos permitió acceder a espacios como los grupos de Facebook en los que interactúan trabajadoras de toda Argentina, y desde los cuales pudimos concretar entrevistas virtuales. En tal sentido, triangulando datos de carácter cuantitativo producidos por la encuesta con la información de las entrevistas y el seguimiento de los espacios virtuales, logramos componer una foto de la situación laboral de las trabajadoras domésticas remuneradas que se inserta en la larga historia de vulnerabilidad que padeció y padece el sector, agudizada hoy por la pandemia. En líneas generales, el contexto actual empeoró los procesos de precarización estructural propios de este sector de trabajo, al tiempo que evidenció el ejercicio de diversas estrategias de los empleadores durante la cuarentena: desde el despido y la reducción del salario, hasta los cambios de categoría y las vacaciones anticipadas. Asimismo, mostramos que más de la mitad de las trabajadoras tenían como única fuente de ingreso el salario de su trabajo, es decir, que el panorama de sus condiciones de vida, ya agravado, era crítico.

Con respecto a los discursos masculinizados sobre la pandemia, observamos que se constituye a partir de un fuerte sentido acerca de la producción de la masculinidad y el tecnicismo científico, que en gran medida contrasta con aquellas tareas que portan significantes femeninos como el trabajo doméstico. Así, se produce una tensión que coloca al trabajo doméstico como lo abyecto frente al discurso pandémico del CoviD-19, profundizando los procesos de desvalorización social intrínsecos a las tareas domésticas remuneradas.

Para finalizar, queremos cerrar este artículo haciendo hincapié en que la pandemia del COVID19 hizo evidente una de las paradojas propias de las sociedades organizadas en el modo de producción capitalista: el trabajo de lo doméstico es una tarea socialmente desvalorizada y desprestigiada, no obstante, fue una de las actividades sobre las que con más premura se discutió su vuelta a la "normalidad".

\footnotetext{
${ }^{31}$ A modo de ejemplo: Télam. (25 de mayo de 2020); Diario Página 12. (09 de julio de 2020).
} 


\section{Agradecimientos}

A Miriam Wlosko (UNLA), con quien hemos realizado el "Informe preliminar de la encuesta a trabajadoras/es de casas particulares y su situación laboral en el contexto de aislamiento por la pandemia de COVID-19 en Argentina". A Anabella Bustos (CEIL-CONICET) quien llevó a cabo el diseño gráfico del informe de la encuesta.

A Mónica Ibáñez, Dora Sánchez, Marcela Irina Muñoz y a las trabajadoras que nos brindaron su tiempo, relataron sus vivencias y compartieron valiosas reflexiones.

\section{Referencias bibliográficas}

Achilli, Elena Libia. (2005). Investigar en antropología. Los desafíos de trasmitir un oficio. Rosario: Laborde Libros Editor.

Ardèvol, Elisenda; Estalella, Adolfo y Domínguez, Daniel. (2008). Introducción. La mediación tecnológica en la práctica etnográfica. En Elisenda Ardèvol, Adolfo Estalella y Daniel Domínguez (Coords.), La mediación tecnológica en la práctica etnográfica (pp. 9-29). Gobierno Vasco: Donostia, Ankulegi Antropologia Elkartea. Recuperado de https://www.ankulegi.org/wp-content/uploads/2012/03/0501Ardevol.pdf

Borderías, Cristina; Carrasco, Cristina y Torns, Teresa. (2011). Introducción. El trabajo de cuidados: antecedentes históricos y debates actuales. En Cristina Borderías, Cristina Carrasco y Teresa Torns (Eds.), El trabajo de cuidados. Historia, Teoría y Políticas (pp. 13-95). Madrid: Libros de la Catarata, Ministerio de Sanidad, Política Social e Igualdad del Gobierno de España.

Bourdieu, Pierre. (2012). La dominación masculina. Barcelona: Anagrama. 
Canevaro, Santiago. (2009a). Empleadoras del servicio doméstico en la Ciudad de Buenos Aires: intimidad, desigualdad y afecto. Avá. Revista de Antropología, (15), 187-207. Recuperado de http://argos.fhycs.unam.edu.ar/handle/123456789/286

Canevaro, Santiago. (2009b). Empleadas domésticas y empleadoras en la configuración del trabajo doméstico en la Ciudad de Buenos Aires: entre la administración del tiempo, la organización del espacio y la gestión de las 'maneras de hacer'. Campos. Revista de Antropología Social, 10(1), 63-86.doi: http://dx.doi.org/10.5380/cam.v10i1.18579

Capogrossi, María Lorena. (2020). "La época de los esclavos se acabó": género y condiciones de trabajo en las empresas de limpieza en Argentina. ÍCONOS, Revista de Ciencias Sociales 24(66), 173-190. doi: https://doi.org/10.17141/iconos.66.2020.3753

Capogrossi, María Lorena; Magallanes, Mariana Loreta y Socaire, Florencia. (2015). Los desafíos de Facebook. Apuntes para el abordaje de las redes sociales como fuente. Revista Antropología Experimental, (15), 47-63. doi: https://doi.org/10.17561/rae.v0i15.2390

Casas, Verónica. (2019). "De las empleadas depende la vida de los patrones". Dones y reciprocidad en el universo laboral de las trabajadoras domésticas en la Ciudad de Buenos Aires. Revista Theomai, Estudios Críticos sobre Sociedad y Desarrollo, (40), 153-170. Recuperado de http://revista-theomai.unq.edu.ar/NUMERO_40/10.\%20Casas_40.pdf

Connell, Robert W. (1997). La organización social de la masculinidad. En Teresa Valdés, José Olavarría (Eds.), Masculinidad/es. Poder y crisis (pp. 113-125). Santiago de Chile: Isis Internacional.

Cutuli, Romina y Pérez, Inés. (2011). Trabajo, género y desigualdad. El caso de las empleadas domésticas en Mar del Plata, 2010-2011. Buenos Aires: Concurso Bicentenario de la Patria, Premio Juan Bialet Massé. 
Diario Página 12. (09 de julio de 2020). La cuarentena de las empleadas domésticas. Diario Página 12. Recuperado de https://www.pagina12.com.ar/277244-la-cuarentena-de-lasempleadas-domesticas

ECETSS. (2018). II Encuesta Nacional a trabajadores sobre Condiciones de Empleo, Trabajo, Salud y Seguridad del Ministerio de Trabajo, Empleo y Seguridad Social. Recuperado de http://www.trabajo.gob.ar/downloads/estadisticas/ecetss/ecetss informe.pdf

Federici, Silvia. (2010). La bruja y el Calibán. Mujeres, cuerpo y acumulación originaria. Buenos Aires: Tinta Limón Ediciones.

Federici, Silvia. (2018). El patriarcado del salario. Críticas feministas al marxismo. Ciudad Autónoma de Buenos Aires: Tinta Limón Ediciones.

Figari, Claudia. (Dir) (2020). El trabajo en los tiempos del COVID-19. CEIL-CONICET Recuperado de http://www.ceil-conicet.gov.ar/publicaciones/el-trabajo-en-los-tiemposdel-covid/

Fuller, Norma. (1997). Fronteras y retos: Varones de clase media del Perú. En Teresa Valdés y José Olavarría (Eds.), Masculinidad/es. Poder y crisis (pp. 139-153). Santiago de Chile, Isis Internacional.

Gorban, Débora. (2012). Empleadas y empleadoras, tensiones de una relación atravesada por la ambigüedad. Revista Española de Investigaciones Sociológicas, (140), 29-48.

Gorban, Débora. (2014). De niñeras, cuidadoras y empleadas domésticas: una mirada sobre los procesos de selección de trabajadoras del cuidado entre familias de clases medias en la ciudad de Buenos Aires. Serie Documentos para Discusión, Instituto de Desarrollo Económico $y \quad$ Social, (16), 3-29. Recuperado de https://publicaciones.ides.org.ar/libro/nineras-cuidadoras-empleadas-domesticas$\underline{\text { mirada-procesos-seleccion-trabajadoras-cuidado }}$ 
Guber, Roxana. (2001). La etnografía. Método, campo y reflexividad. Buenos Aires: Grupo Editorial Norma.

Hine, Christine. (2004). Etnografía virtual. Barcelona: Editorial UOC.

Infobae. (21 de abril de 2020) Alberto Fernández: "El coronavirus es un enemigo invisible e indescifrable, pero no tengo dudas de que tendremos éxito". Infobae. Recuperado de https://www.infobae.com/politica/2020/04/21/alberto-fernandez-el-coronavirus-es-unenemigo-invisible-e-indescifrable-pero-no-tengo-dudas-de-que-tendremos-exito/

Instituto de Estudios Sociales en Contexto de Desigualdades. (2020). Desigualdades en el marco de la pandemia. Reflexiones y desafios. UNPAZ. Recuperado de https://www.unpaz.edu.ar/node/3932.

Kofes, María Suely. (2001). Mulher, Mulheres-Identidade, Diferença e Desigualdad en a Relação entre Patroas e Empregadas. Campinas: Unicamp.

Lexartza, Larraitz; Chaves, María José y Carcedo, Ana. (2016). Políticas de formalización del trabajo doméstico remunerado en América Latina y el Caribe. Lima: OIT, Oficina Regional para América Latina y el Caribe, FORLAC.

López Mourelo, Elva. (2020). La COVID-19 y el trabajo doméstico en Argentina. Argentina: OIT, Oficina de País de la OIT para la Argentina. Recuperado de https://www.ilo.org/wcmsp5/groups/public/---americas/---ro-lima/---ilobuenos_aires/documents/publication/wcms 742115.pdf

Magliano, María José. (2015). Interseccionalidad y migraciones: potencialidades y desafíos. Revista Estudos Feministas, 23(3), 691-712. doi: https://doi.org/10.1590/0104$\underline{026 \times 2015 v 23 n 3 p 691}$ 
Magliano, María José. (2017). Las trabajadoras invisibles: experiencias laborales de mujeres migrantes en Argentina. Revista Latinoamericana de Antropología del Trabajo, 1(1), 123. Recuperado de http://www.ceil-conicet.gov.ar/ojs/index.php/lat/article/view/228

Menéndez, Eduardo L. (1988). Modelo Médico Hegemónico y Atención Primaria. Segundas Jornadas de Atención Primaria de la Salud. Buenos Aires. Recuperado de https://www.psi.uba.ar/academica/carrerasdegrado/psicologia/sitios catedras/electivas/8 $16 \mathrm{rol}$ psicologo/material/unidad2/obligatoria/modelo medico.pdf

Ministerio de Salud de la Nación. (2020). Salud confirma el primer caso de coronavirus en el país. Recuperado de https://www.argentina.gob.ar/noticias/salud-confirma-el-primercaso-de-coronavirus-en-el-pais

Ministerio de Trabajo, Empleo y Seguridad Social, MTEySS. (2005). Situación laboral del servicio doméstico en Argentina. Buenos Aires: Subsecretaría de Programación Técnica y Estudios Laborales. $\quad$ Recuperado de https://dgfss.files.wordpress.com/2015/03/informe_situacionlaboraldelserviciodomestic oenlaargentina_mtess_sf.pdf

Ministerio De Trabajo, Empleo y Seguridad Social, MTEySS. (2014a). Avances en la registración laboral de las trabajadoras en casas particulares a partir del nuevo marco legal. Recuperado de http://www.trabajo.gob.ar/downloads/destacados/140729 casasparticulares.pdf

Ministerio de Trabajo Empleo y Seguridad Social, MTEySS. (2014b). Protección y Seguridad Social en la Argentina. Resultados de la Encuesta Nacional de Protección y Seguridad Social 2011 (ENAPROSS). Ciudad Autónoma de Buenos Aires: Ministerio de Trabajo, $\begin{array}{lllll}\text { Empleo } & \text { y } & \text { Seguridad } & \text { Social. Recuperado de }\end{array}$ http://www.trabajo.gob.ar/downloads/estadisticas/enapross/Libro_ENAPROSS_interior. pdf 
Ministerio de Trabajo, Empleo y Seguridad Social. (2020). Situación y evolución del trabajo registrado- Datos de abril de 2020. Recuperado de http://www.trabajo.gob.ar/downloads/estadisticas/trabajoregistrado/trabajoregistrado_20 04_informe.pdf

Murillo, Soledad. (1996). El mito de la vida privada. De la entrega al tiempo propio. Madrid: Siglo XXI.

Organización Internacional De Trabajo, OIT. (2016). Protección social del trabajo doméstico. En Documentos de política de protección social, 16, Ginebra. Recuperado de https://www.ilo.org/wcmsp5/groups/public/---ed_protect/--soc_sec/documents/publication/wcms_458939.pdf

Palermo, Hernán M. (2017). La producción de la masculinidad en el trabajo petrolero. Buenos Aires: Editorial Biblos.

Pereyra, Francisca. (2012). La regulación laboral de las trabajadoras domésticas en Argentina. Situación actual y perspectivas. En Valeria Esquivel, Eleonor Faur y Elizabeth Jelin (Eds.), Las lógicas del cuidado infantil. Entre las familias, el Estado y el mercado (pp. 165-200). Buenos Aires: IDES.

Poblete, Lorena. (2014). Esa vieja dupla: empleo y protecciones sociales... Reflexiones en torno a la regulación del servicio doméstico en Argentina. Serie Documentos para discusión del PESEI, 16. Recuperado de https://publicaciones.ides.org.ar/libro/viejadupla-empleo-protecciones-sociales-reflexiones-torno-regulacion-servicio-domestico

Poblete, Lorena. (2016). Empleo y protecciones sociales, ¿dos caras de la misma moneda? Reflexiones en torno a la regulación del servicio doméstico en Argentina. Revista Latinoamericana de Derecho Social, 22, 153-180. doi: https://doi.org/10.1016/j.rlds.2015.09.002 
Rodríguez Yebra, Martín. (28 de marzo de 2020). Coronavirus: un encierro largo y más estricto, la próxima etapa de la guerra. Diario La Nación. Recuperado de https://www.lanacion.com.ar/politica/coronavirus-encierro-largo-mas-estricto-proximaetapa-nid2348396

Rubinstein, Adolfo. (17 de mayo de 2020). Coronavirus. Para ganar la batalla hay que salir de la trinchera. Diario La Nación. Recuperado de https://www.lanacion.com.ar/opinion/coronavirus-para-ganar-batalla-hay-salir$\underline{\text { trinchera-nid2366455 }}$

Scott, Joan W. (2008). El género: Una categoría útil para el análisis histórico. En Marta Lamas (Comp.), El género. La construcción cultural de la diferencia sexual (pp. 265-302). México: PUEG.

Télam. (25 de mayo de 2020). Empeoró la situación laboral de más de la mitad de las empleadas domésticas. Télam Recuperado de https://www.telam.com.ar/notas/202005/468063empeoro-la-situacion-laboral-de-mas-de-la-mitad-de-las-empleadas-domesticas.html

Telenueve. (24 de marzo de 2020). Catherine Fulop hace la cuarentena con su empleada doméstica. $\quad$ archivo de video]. Recuperado de https://www.youtube.com/watch?v=rF5qt5iGfi4

Trajtemberg, David. (2016). Políticas públicas laborales tras doce años de gobierno de Néstor Kirchner y Cristina Fernández, Análisis, (17), 1-19. Recuperado de https://library.fes.de/pdf-files/bueros/argentinien/13061.pdf

Wlosko, Miriam; Palermo, Hernán y Casas, Verónica. (2020). "Informe preliminar de la encuesta a trabajadoras de casas particulares y su situación laboral en el contexto de aislamiento por la pandemia de COVID-19 en Argentina". Recuperado de http://www.ceilconicet.gov.ar/2020/05/informe-encuesta-a-trabajadorases-de-casas-particulares-y-su- 
$\underline{\text { situacion-laboral-en-el-contexto-de-aislamiento-por-la-pandemia-de-covid-19-en-la- }}$ argentina/

\section{VERÓNICA L. CASAS}

Licenciada en Ciencias Antropológicas (UBA). Becaria doctoral del Centro de Estudios e Investigaciones Laborales (CEIL-CONICET-Argentina) y se encuentra cursando la maestría de Estudios Latinoamericanos del Trabajo en la Facultad de Filosofía y Letras (UBA). Investiga temas de género y trabajo, específicamente aquellas líneas que abordan los trabajos vinculados al cuidado remunerado. Realizó su tesis de licenciatura sobre el sector de trabajo doméstico remunerado, campo que continúa investigando en la actualidad.

\section{HERNÁN M. PALERMO}

Doctor en Ciencias Antropológicas. Investigador del Centro de Estudios e Investigaciones Laborales (CEIL-CONICET-Argentina). Director de la Revista Latinoamericana de Antropología del Trabajo perteneciente al CEIL de Argentina y al CIESAS de México. Director de la maestría en Estudios Latinoamericanos del Trabajo de la Facultad de Filosofía y Letras, UBA. Sus líneas de investigación abordan temas de antropología latinoamericana del trabajo, géneros y trabajo, y la relación entre las nuevas tecnologías digitales y el trabajo. 